\title{
Increasing trend in atmosphere helium from 1975 to 2019
}

\author{
BENJAMIN BIRNER*, JEFFREY SEVERINGHAUS, RALPH F. \\ KEELING
}

Scripps Institution of Oceanography, UC San Diego, La Jolla, CA 92093, USA; (*correspondence: bbirner@ucsd.edu)

The release of crustal helium associated with global fossil fuel extraction is thought to increase atmospheric ${ }^{4} \mathrm{He}$ concentrations and thus reduce the atmospheric ${ }^{3} \mathrm{He} /{ }^{4} \mathrm{He}$ isotope ratio ${ }^{[1,2]}$. Early observational studies indeed found evidence of such an anthropogenic signal ${ }^{[3-5]}$ but were challenged by several recent investigations that detected no significant atmospheric ${ }^{3} \mathrm{He} /{ }^{4} \mathrm{He}$ trend ${ }^{[6-8]}$.

Here we present a novel analytical mass spectrometry technique that can constrain relative changes in the atmospheric helium-to-nitrogen $\left({ }^{4} \mathrm{He} / \mathrm{N}_{2}\right)$ ratio at an unprecedented precision of $<50$ per meg $\left(1\right.$ per meg $=10^{-4} \%$, $1 \sigma)$ for a single air sample. The new method was used to analyze 26 air samples that are stored in high pressure gas cyclinders at Scripps Institution of Oceanography and span the age range 1975 - 2019. Gas samples were screened for artifectual fractionation by leakage.

Preliminary results indicate a increase in ${ }^{4} \mathrm{He} / \mathrm{N}_{2}$ of +1.8 per mil from 1975 through 2019, corresponding to an average rate of +40 per meg per year. The record also suggests the possibility of accelerated ${ }^{4} \mathrm{He}$ release after 1990 . This ties together observations and theoretical predictions of an anthropogenic signature in atmospheric helium and places tight boundaries on the trend. The implied $\sim 1.8$ per mil change in the atmospheric ${ }^{3} \mathrm{He} /{ }^{4} \mathrm{He}$ since 1975 challenges the common view of ambient air as a time-invariant reference gas.

[1] Pierson-Wickmann, A. C., Marty, B. \& Ploquin, A. (2001) Earth and Planetary Science Letters 194, 165-175. [2] Oliver, B. M., Bradley, J. G. \& Farrar IV, H. (1984) Geochimica et Cosmochimica Acta 48, 1759-1767. [3] Sano, Y., Wakita, H., Makide, Y. \& Tominaga, T. (1991) Geophysical Research Letters 18, 486-4888. [4] Sano, Y., Wakita, H., Makide, Y. \& Tominaga, T. (1989) Geophysical Research Letters 16, 1371-1374. [5] Sano, Y., Furukawa, Y. \& Takahata, N. (2010) Geochimica et Cosmochimica Acta 74, 4893-4901. [6] Lupton, J. \& Evans, L. (2013) Geophysical Research Letters 40, 6271-6275. [7] Mabry, J. C. et al. (2015) Earth and Planetary Science Letters 428, 134-138.[8] Boucher, C., Marty, B., Zimmermann, L. \& Langenfelds, R. (2018) Geochemical Perspectives Letters 6, 23-27. 